\title{
How Do Californians Define Safe Sex?
}

\author{
Joel M. Moskowitz ${ }^{1}$, Assunta Ritieni ${ }^{2}$, Maya Tholandi ${ }^{2}$, Qiang Xia ${ }^{2}$ \\ ${ }^{1}$ University of California Berkeley, Center for Family and Community Health \\ ${ }^{2}$ California Department of Health Services, Office of AIDS
}

\begin{abstract}
Objectives: We examined definitions of "safe sex" among adults in California, and assessed whether definitions varied by sociodemographic characteristics and sexual behavior. Methods: We analyzed crosssectional data from the "AIDS Knowledge, Attitudes, Beliefs, and Behaviors (KABB) Survey," a statewide telephone survey of California adults conducted in 2000. Results: The four most common definitions of safe sex were condom use (68.0\%), abstinence (31.1\%), monogamy (28.4\%), and safe partner (18.7\%). Definitions were associated with sex, age, race/ethnicity, education, and number of sexual partners in the past 12 months. Conclusions: Most adults defined safe sex in terms of condom use either alone or in conjunction with other methods. Individuals' definitions were complex and varied across sociodemographic groups which suggest the need for policies and programs which reflect this diversity.
\end{abstract}

(C) 2006 Californian Journal of Health Promotion. All rights reserved.

Keywords: safe sex, survey, general population, California

The concept of "safe sex" was derived in response to the HIV/AIDS epidemic. As such, early definitions of this term focused on male homosexuals, the community where the outbreak began. The earliest reference to this term in the professional literature was in a November 1984 paper discussing the psychological impact of HIV/AIDS on homosexual men and the need to educate them about sexual practices (Morin, Charles \& Malyon, 1984). The term first appeared in the New York Times the following year in an article which noted that some doctors counseled their AIDS patients about the practice of safe sex (Whitmore, 1985). The concept included limiting the number of sexual partners, using prophylactics, avoiding bodily fluid exchange, and resisting use of drugs that reduced inhibitions for high-risk sexual behavior (Collins, 1985). In 1985, the Coalition for Sexual Responsibility drafted safe sex guidelines to promote the distribution and use of condoms "to eliminate the exchange of body fluids during anal intercourse or oral sex" (Lindsey, 1985).

By 1986 the notion of "safe sex" spread from the walls of gay bathhouses to college campuses and the general population (Nordheimer, 1986). Colleges promoted safe sex practices such as condom use, limits on the number of sexual partners, and knowledge about potential partners' sexual history and prior drug abuse (Nordheimer, 1986). Sex workers called on the governments of Western Europe and the United States (U.S.) to conduct extensive sex education programs that stressed the need for safe sex as defined by condom use (Miller, 1986). The same year, an 88-page book entitled, Safe Sex in the Age of AIDS, was published that discussed a "positive approach" to safe sex labeling abstinence and monogamy a "negative approach" (Institute for the Advanced Study of Human Sexuality, 1986). Sexual behaviors were classified as either "safe," "possibly safe," or "unsafe." Safe sex included dry kissing, hugging, massage, body-to-body rubbing, mutual masturbation, exhibitionism and voyeurism, telephone sex, sado-masochism without bruising or bleeding, and use of separate sex toys. At that time, latex condoms were considered "possibly safe" due to concerns that the virus which causes AIDS might traverse latex. With increasing concern about heterosexual transmission of HIV, health 
officials called for sex education for children as well as safe sex education for homosexual and bisexual males (Eckholm, 1986). Health professionals defined safe sex for adolescents to include "judicious selection of sexual partners, the use of mechanical and chemical barriers during intercourse, and avoidance of sex practices such as those in which bodily fluids are exchanged" (Slevin \& Marvin, 1987).

Politicians and the faith community were concerned about the mass dissemination of a safe sex message based solely on health considerations. A debate ensued between Surgeon General C. Everett Koop and Secretary of Education William J. Bennett which resulted in the issuance of a joint statement by the Federal Government that "young people should be taught that the best precaution is abstinence until it is possible to establish a mutually faithful monogamous relationship" (Werner, 1987). However, Dr. Koop also advocated for condom use among those who were sexually active and called for allowance of condom advertisements on television. Although Catholic bishops in the U.S. issued "safer sex" guidelines which included condom use, two years later in 1989 the Vatican attacked these guidelines and urged chastity and heterosexual marriage (Lattin, 1989).

To date, the public health community has embraced "safe sex" as a harm reduction strategy because the concept incorporates medical and epidemiologic knowledge about HIV transmission (Kippax \& Race, 2003). The concept has been broadened to include sexual abstinence (or the absence of sexual intercourse) because abstinence is safer than sexual intercourse with protection from barrier methods. The Centers for Disease Control and Prevention (CDC) has discussed safe sex (including abstinence) as a strategy for prevention of HIV and sexually transmitted diseases (STDs) in its annual performance plans, "Safe sexual behavior, including abstinence and use of barrier protection, can dramatically limit the magnitude of the STD epidemic in the U.S." (CDC, 2004). The Bush Administration, however, has adopted an abstinence-only approach to AIDS prevention (Block, 2004). In response, The Lancet questioned the effectiveness of abstinence-only programs based upon recommendations of expert panels sponsored by the Surgeon General's Office and the Institute of Medicine (Lancet, 2002).

The concept of safe sex has affected cultural norms and sexual practices, most notably with regard to increased condom use (Kippax \& Race, 2003); however, the empirical basis for this assertion is limited. Individuals' definitions of safe sex may have an indirect influence on their sexual behavior. In one study, heterosexual males' beliefs about the outcomes of practicing abstinence, mutual monogamy, or condom use varied by marital status, race/ethnicity, and education. Their beliefs predicted their concordant sexual behaviors with steady partners, but not casual partners, reported in a follow-up interview four months later (Gillmore et al., 2003).

A search of the literature reveals a paucity of data regarding how the general population defines "safe sex." The present study examines definitions of safe sex among adults in California based upon a general population survey. The study also examines how definitions vary across sociodemographic groups and among individuals with differing numbers of sexual partners.

\section{Methods}

The study was based upon data collected from a population-based survey of California adults aged 18 and older, which examined HIV/AIDS knowledge, attitudes, beliefs, and behaviors. Under the direction and supervision of the University of California Berkeley Center for Family and Community Health $(\mathrm{CFCH})$, the Communication Sciences Group/Survey Methods Group conducted 1,739 telephone interviews between April and June, 2000. Trained interviewers conducted the interviews using a computer-assisted telephone interview (CATI) system. To minimize question nonresponse, a sex-matching question was used. If the respondent was a different sex than the interviewer, the interviewer asked the person if she/he would prefer being interviewed by someone of his or her own sex. The interviews 
were conducted in either English or Spanish depending upon the participant's preference. On average, the interviews lasted approximately 22 minutes. All participants were read a consent form approved by the California Health and Human Services Agency and the University of California, Berkeley Committee for the Protection of Human Subjects. A detailed description of the methods and results for the "2000 California AIDS Knowledge, Attitudes, Beliefs, and Behaviors (KABB) Survey" is available (Moskowitz, Henneman \& Young Holt, 2002).

\section{Sampling Design}

A modified random-digit-dialing (RDD) sample was employed. Four strata of roughly equal size were constructed: (1) Los Angeles County and surrounding Primary Metropolitan Statistical Areas (PMSAs), (2) San Diego and Orange Counties and adjacent PMSAs, (3) San Francisco Bay Area PMSAs and (4) the rest of the state of California (Non-Metro Stratum). To ensure generalizability of the results, a random sampling of 8,803 telephone numbers in California was performed; 3,697 were eliminated as confirmed non-residential households. All residential households with an individual over the age of 18 were considered eligible.

Each telephone number was dialed during daytime, evening and weekend hours to maximize the likelihood of reaching someone at home. All active numbers were dialed until: 1) a final disposition was obtained, 2) 40 attempts were completed, or 3) the fielding period concluded. An average of 11.25 call attempts were made to all numbers over a ten-week period.

Sample weights were developed to account for different probabilities of selection depending on the number of telephone lines and number of eligible adults in a household. Post-stratification weights, which incorporate the sampling weights, were then used to adjust the sample population to the 2000 projections provided by the California Department of Finance for sex, race/ethnicity and age groups in California.
The survey obtained a $35 \%$ overall response rate based upon a formula where the eligibility of each sample unit is not known in advance (American Association for Public Opinion Research, 2004). The cooperation rate, defined as the proportion of all known eligible households where a respondent was interviewed, was $69 \%$. This paper focuses on 1,698 participants (of 1,739) who provided complete data on all questions used in this study.

\section{Survey Instrument}

Where possible, questions were adapted from prior surveys. Survey questions were subjected to pilot-testing and expert review. After the questionnaire was completed, the questions were translated into Spanish and then back-translated into English using another translator.

The following question was used to assess definitions of safe sex: "According to the information you have, how would you define safe sex?" Interviewers probed for multiple responses in order to obtain a complete definition. The responses were coded into 11 pre-defined categories: (1) reduce number of sex partners; (2) no exchange of bodily fluids; (3) use condoms; (4) avoid anal intercourse; (5) be monogamous (one partner); (6) be celibate (be abstinent); (7) take sanitary precautions / be clean; (8) know partners / be aware of partner's background; (9) avoid high-risk partners; (10) having sex with only one person who is not infected; and (11) get tested for HIV. Responses that did not fit into these categories were coded as "other" and were entered verbatim into the computer. The 1,698 participants provided 3,093 responses to this question for an average of 1.82 responses per participant $(\mathrm{SD}=0.97)$. Only $8.3 \%$ of the 3,093 responses were classified as "other." Based upon a priori criteria, the authors re-categorized the pre-structured responses into four composite definitions: Condom Use (based upon responses to category \#3), Abstinence (category \#6), Monogamy (categories \#5 and \#10) and Safe Partner (categories \#8 and \#9). For Condom Use and Abstinence, the variables were coded 1 if the requisite category was reported and coded 0 if it was not. For Monogamy and Safe Partner, the variables were coded 1 if either of the requisite categories was 
reported, and 0 if neither was reported. "Don't know" or "refused" answers were coded 0 on all four variables. The four definitions accounted for $82.4 \%$ of all responses to the safe sex question. This paper focuses on these four definitions.

The study included four sociodemographic variables and a measure of sexual activity in the previous 12 months. The demographic variables included sex, age (in years), race/ethnicity, and education (in years). The race/ethnicity variable was categorized as White, African American, Hispanic, and "other," where "other" included Native Americans, Asian Americans and Pacific Islanders. Sexual activity during the previous 12 months was assessed by the following question, "During the last 12 months, with how many people have you had sexual intercourse? Again, by sexual intercourse I mean vaginal or anal sex."

\section{Statistical Analyses}

Stata 8.0 was used for all statistical analyses. With the exception of the first set of analyses in Appendix A, which summarizes unweighted characteristics of the study sample, the analyses employed weighted data and used the appropriate Stata SVY procedure to obtain standard error estimates that account for the complex survey sample design (Stata Corporation, 2003).

Multivariable logistic regression was performed to examine factors associated with sociodemographic characteristics of the sample. Sociodemographic variables included in the model were selected due to significance in initial univariate analyses (chi-square) or because they were considered relevant $a$ priori.

\section{Results}

\section{Sample Characteristics}

Characteristics of the study sample are summarized in Appendix A. Unweighted sample sizes and percentages are provided along with weighted percentages and $95 \%$ confidence intervals (CI). The typical (i.e., mode) participant in the survey was female, 25-44 years of age, White, had 16 or more years of education, and had one sexual partner in the previous 12 months.

\section{Definitions of Safe Sex}

The four most common definitions of safe sex provided by adults in California were condom use, mentioned by $68.0 \%(95 \% \mathrm{CI}=65.5,70.9)$ of the population; abstinence, mentioned by $31.1 \%(95 \%$ CI $=28.5,33.7)$; monogamy, mentioned by $28.4 \%(95 \% \mathrm{CI}=25.6,31.1)$; and safe partner, mentioned by $18.7 \%$ of the population $(95 \% \mathrm{CI}=16.3,21.2)($ Table 1$)$.

Table 1

Definitions of Safe Sex, Frequency Distribution: California Adults 2000 (N=1698)*

\begin{tabular}{|c|c|c|c|c|c|}
\hline Condom Use & Abstinence & Monogamy & Safe Partner & $\mathbf{9}$ & $\mathbf{9 5 \%}$ CI \\
\hline $\mathrm{X}$ & & & & 26.3 & $23.8,28.8$ \\
\hline $\mathrm{X}$ & $\mathrm{X}$ & & & 15.3 & $13.3,17.2$ \\
\hline $\mathrm{X}$ & & & & 10.2 & $8.4,12.1$ \\
\hline $\mathrm{X}$ & & $\mathrm{X}$ & & 9.7 & $7.9,11.4$ \\
\hline & & $\mathrm{X}$ & & 7.9 & $6.4,9.4$ \\
\hline & $\mathrm{X}$ & & & 7.8 & $6.1,9.4$ \\
\hline $\mathrm{X}$ & $\mathrm{X}$ & $\mathrm{X}$ & & 7.1 & $5.6,8.5$ \\
\hline $\mathrm{X}$ & & $\mathrm{X}$ & $\mathrm{X}$ & 2.5 & $2.4,4.5$ \\
\hline & & $\mathrm{X}$ & $\mathrm{X}$ & 2.4 & $1.6,3.3$ \\
\hline & & & $\mathrm{X}$ & 2.2 & $1.2,3.2$ \\
\hline $\mathrm{X}$ & $\mathrm{X}$ & & $\mathrm{X}$ & 2.2 & $1.4,2.9$ \\
\hline $\mathrm{X}$ & $\mathrm{X}$ & $\mathrm{X}$ & & 1.5 & $0.7,2.3$ \\
\hline & $\mathrm{X}$ & $\mathrm{X}$ & $\mathrm{X}$ & 0.8 & $0.3,1.3$ \\
\hline & $\mathrm{X}$ & & $\mathrm{X}$ & 0.5 & $0.2,0.8$ \\
\hline & $\mathrm{X}$ & $\mathrm{X}$ & $\mathrm{X}$ & 0.3 & $0.0,0.6$ \\
\hline
\end{tabular}



* This table summarizes combinations of the four most common single definitions of safe sex. An X denotes that
a specific definition was part (or all) of the combined definition. The row with no X's represents individuals who
had no definition or whose definition excluded the four most common definitions.

Since respondents were allowed to provide multiple definitions, for Table 1 above we summarized the frequency distribution of the combinations of definitions obtained for the four most common definitions. The most common composite definition of safe sex provided by $26.3 \%$ of the population was condom use alone (i.e., with no other method mentioned). Next most common, accounting for $15.3 \%$ of the population, was the combination of condom use and abstinence. Over ten percent $(10.2 \%)$ of the population either did not provide any definition of safe sex $(3.9 \%)$ or provided a definition that excluded the four most common definitions $(6.3 \%)$.

The results of four multiple logistic regression models which examined the sociodemographic predictors of the safe sex definitions are summarized in Table 2. Condom use as a safe sex definition was significantly predicted by age and race/ethnicity. Condom use was mentioned most often by adults aged 18-25 years and least often by adults 65 years or older. Hispanics were less likely to mention condom use than NonHispanic Whites. Abstinence was significantly predicted by sex, race/ethnicity and education. Abstinence was more likely to be cited by females, African Americans, and respondents with 12 or more years of education. Monogamy was predicted by sex, age, and race/ethnicity. It was mentioned most often by males, adults aged 25-64 years, and by Hispanics. Safe partner was significantly predicted by age and education and was mentioned most often by adults aged 45-64 years and those with 16 or more years of education.

Table 2

Predictors of Four Safe Sex Definitions: Multiple Logistic Regression Analyses: California Adults $2000(\mathrm{~N}=1698)^{*}$

\begin{tabular}{|l|l|l|l|l|l|l|l|l|}
\hline & \multicolumn{2}{|c|}{ Condom Use } & \multicolumn{2}{c|}{ Abstinence } & \multicolumn{2}{c|}{ Monogamy } & \multicolumn{2}{c|}{ Safe Partner } \\
\hline \multicolumn{1}{|c|}{ Predictors } & $\begin{array}{c}\text { Odds } \\
\text { Ratio }\end{array}$ & $\begin{array}{c}95 \% \\
\text { C.I. }\end{array}$ & $\begin{array}{c}\text { Odds } \\
\text { Ratio }\end{array}$ & $\begin{array}{c}95 \% \\
\text { C.I. }\end{array}$ & $\begin{array}{c}\text { Odds } \\
\text { Ratio }\end{array}$ & $\begin{array}{c}95 \% \\
\text { C.I. }\end{array}$ & $\begin{array}{c}\text { Odds } \\
\text { Ratio }\end{array}$ & $\begin{array}{c}95 \% \\
\text { C.I. }\end{array}$ \\
\hline $\begin{array}{l}\text { Sex } \\
\text { (ref=Female) }\end{array}$ & & & & & & & & \\
\hline Male & .94 & $.73,1.22$ & $.55^{*}$ & $.43, .71$ & $1.40^{*}$ & $1.06,1.83$ & 1.36 & $1.00,1.84$ \\
\hline $\begin{array}{l}\text { Age Group (years) } \\
\text { (ref=18-25) }\end{array}$ & & & & & & & & \\
\hline $25-44$ & $.49^{*}$ & $.32, .75$ & 1.05 & $.73,1.52$ & $2.46^{*}$ & $1.57,3.86$ & 1.56 & $.94,2.57$ \\
\hline $45-64$ & $.34^{*}$ & $.21, .55$ & 1.00 & $.66,1.51$ & $2.26^{*}$ & $1.37,3.74$ & $2.25^{*}$ & $1.32,3.85$ \\
\hline $65+$ & $.18^{*}$ & $.11, .30$ & .89 & $.55,1.44$ & 1.25 & $.66,2.36$ & 1.54 & $.80,2.94$ \\
\hline $\begin{array}{l}\text { Race/Ethnicity } \\
\text { (ref= White) }\end{array}$ & & & & & & & & \\
\hline African-American & .71 & $.45,1.14$ & $2.06^{*}$ & $1.35,3.14$ & 1.33 & $.80,2.21$ & .86 & $.47,1.56$ \\
\hline Hispanic & $.50^{*}$ & $.36, .70$ & .74 & $.52,1.06$ & $1.72^{*}$ & $1.20,2.47$ & 1.34 & $.87,2.07$ \\
\hline Other & .69 & $.38,1.23$ & .65 & $.38,1.10$ & 1.48 & $.83,2.65$ & .89 & $.43,1.81$ \\
\hline $\begin{array}{l}\text { Education (years) } \\
\text { (ref=<12) }\end{array}$ & & & & & & & & \\
\hline 12 & 1.24 & $.83,1.85$ & $2.55^{*}$ & $1.56,4.17$ & .80 & $.51,1.24$ & .85 & $.47,1.53$ \\
\hline $13-15$ & 1.46 & $.95,2.25$ & $2.55^{*}$ & $1.54,4.21$ & .85 & $.53,1.36$ & 1.65 & $.90,3.00$ \\
\hline $16+$ & 1.27 & $.82,1.96$ & $2.86^{*}$ & $1.71,4.81$ & .89 & $.55,1.44$ & $1.94^{*}$ & $1.06,3.55$ \\
\hline
\end{tabular}

ref $=$ reference category; ${ }^{*} \mathrm{p}<.05$ 
The results of four multiple logistic regression models which examined the associations of the number of sexual partners with the safe sex definitions after controlling for sociodemographic factors (sex, age, race/ethnicity, and education) are summarized in Table 3. The number of sexual partners was significantly related to whether respondents mentioned abstinence, monogamy, or safe partner, but this variable was not related to condom use. Abstinence was mentioned more often by adults with no sexual partner in the past 12 months, and both monogamy and safe partner were mentioned more often by adults with one sexual partner.

Table 3

Adjusted Odds Ratios for Associations between Number of Sexual Partners with Four Definitions of Safe Sex: California Adults $2000(\mathrm{~N}=1698)^{* *}$

\begin{tabular}{|c|c|c|c|c|c|c|c|c|}
\hline & \multicolumn{2}{|c|}{ Condom Use } & \multicolumn{2}{|c|}{ Abstinence } & \multicolumn{2}{|c|}{ Monogamy } & \multicolumn{2}{|c|}{ Safe Partner } \\
\hline $\begin{array}{l}\text { Number sexual partners } \\
\text { in past } 12 \text { months }\end{array}$ & $\begin{array}{c}\text { Adj. } \\
\text { Odds } \\
\text { Ratio }\end{array}$ & $\begin{array}{c}95 \% \\
\text { C.I. }\end{array}$ & $\begin{array}{l}\text { Adj. } \\
\text { Odds } \\
\text { Ratio }\end{array}$ & $\begin{array}{c}95 \% \\
\text { C.I. }\end{array}$ & $\begin{array}{c}\text { Adj. } \\
\text { Odds } \\
\text { Ratio }\end{array}$ & $\begin{array}{c}95 \% \\
\text { C.I. }\end{array}$ & $\begin{array}{c}\text { Adj. } \\
\text { Odds } \\
\text { Ratio }\end{array}$ & $\begin{array}{c}95 \% \\
\text { C.I. }\end{array}$ \\
\hline (ref $=$ no partners $)$ & 1 & & 1 & & 1 & & 1 & \\
\hline 1 Partner & 0.85 & $0.61,1.18$ & $0.55^{*}$ & $0.40,0.75$ & $2.17 *$ & $1.43,3.29$ & $1.65^{*}$ & $1.10,2.47$ \\
\hline$\geq 2$ Partners & 0.98 & $0.56,1.69$ & $0.55^{*}$ & $0.33,0.90$ & 1.40 & $0.75,2.61$ & 1.27 & $0.69,2.34$ \\
\hline
\end{tabular}

\section{Discussion}

This descriptive study is the first general population study which examines individuals' definitions of safe sex. Almost all (96.1\%) adults in California were able to provide a definition for the term "safe sex." Condom use, was by far the most common definition. Other common definitions included abstinence, monogamy, and safe partner. Because most adults provided more than one definition, we examined their composite definitions. Based upon the four most common definitions, the most popular composite definition was Condom Use alone. This was reported by over one-fourth $(26.3 \%)$ of the population. The next most popular composite definition included Condom Use with either abstinence $(15.3 \%)$, monogamy $(9.7 \%)$, or safe partner $(7.9 \%)$. Condom use either alone or in combination with other common methods accounted for more than two-thirds of adults' definitions of safe sex. Although abstinence was the second most common definition of safe sex (31.1\%), only $7 \%$ mentioned abstinence alone. More than three-fourths (77\%) of those who mentioned abstinence, mentioned it in conjunction with other common methods, especially condom use $(72 \%)$.

Definitions of safe sex varied across sociodemographic groups. As compared to females, males were more likely to mention monogamy and less likely to mention abstinence. Condom use was mentioned most often by adults aged 18-24 years and tended to decrease with age. Adults aged 25-64 years were most likely to mention monogamy, and those aged 45-64 years were most likely to mention safe partner. African Americans were most likely to mention abstinence. Hispanics were least likely to mention condom use and most likely to mention monogamy. Adults with 12 or more years of education were more likely to mention abstinence, and those with 16 or more years of education were more likely to mention safe partner.

Safe sex definitions were associated with individuals' sexual behavior, specifically the number of sexual partners they reported in the past year. After controlling for socio- 
demographic differences, abstinence was mentioned more often by adults with no sexual partner, and monogamy and safe partner were mentioned more often by adults with one sexual partner. Condom use mentions were not associated with the number of sexual partners. These observed associations seemed to make logical sense.

The current study has several limitations. Like other telephone surveys it is subject to potential non-response and response biases of unknown magnitude. The $35 \%$ overall response rate for this survey was less than desired; however, it is comparable to other major surveys conducted in California. For example, the 2001 California Health Interview Survey had a 38\% overall adult response rate (UCLA Center for Health Policy Research. 2002). The sensitive nature of some questions in our survey (e.g., number of sexual partners) may have contributed to underreporting. Although the results suggest that definitions of safe sex are related to sexual behavior, the cross-sectional nature of this study is not designed to test such hypotheses. More research is needed to understand the relationship between individuals' definitions of safe sex and their sexual behavior.

In recent years, many HIV prevention organizations, threatened with loss of funding, have been forced to alter their educational materials. The CDC "has become a case study in the pitched battle between science and ideology" (Block, 2004). The Lancet (2002) noted that due to political interference from the U.S. Administration, "U.S. and international sex education programmes promote the view that the only sensible approach to avoiding unwanted pregnancy and sexually transmitted infections is abstinence until marriage, followed by life-long monogamy."

The present study found that the vast majority of adults have a multidimensional definition of safe sex. Most incorporated condom use and other methods (e.g., safe partner as well as monogamy) into their definitions. Only a minority defined safe sex in terms of abstinence, and most of these individuals incorporated condom use and other common methods into their definitions. Safe sex definitions varied across sociodemographic groups. That individuals' definitions are not unidimensional suggests that public health messages aimed at educating the public about HIV and STD transmission should reflect this complexity. Further, these findings strongly suggest that programs that try to influence sexual behavior to reduce the risk of HIV and STD transmission should consider the diversity of views about safe sex among different subgroups as defined by sex, age, race/ethnicity, education, and number of sexual partners.

\section{References}

American Association for Public Opinion Research. (2004). Standard definitions: Final dispositions of case codes and outcome rates for surveys (Online Edition 3.1 revised February, 2005). Ann Arbor, MI: Author. Retrieved June 29, 2005, from http://www.aapor.org/pdfs/standarddefs2004.pdf

Block, J. (2004). Science gets sacked. International Journal of Health Services, 34, 177-9.

Centers for Disease Control and Prevention. (February, 2004). Centers for Disease Control and Prevention annual performance plan and report. Final FY 2005 GPRA annual performance plan. Revised final FY 2004 GPRA annual performance plan. FY 2003 GPRA annual performance report. Atlanta, GA: Author. Retrieved June 29, 2005, from http://www.cdc.gov/od/perfplan/2004/2004perf.pdf

Collins, G. (1985, July 22). Impact of AIDS: Patterns of homosexual life changing. New York Times, p. B4.

Eckholm, E. (1986, October 28). Heterosexuals and AIDS: The concern is growing. New York Times, p. C1. 
Gillmore, M. R., Stielstra, S., Huang, B., Baker, S. A., Beadnell, B., \& Morrison, D. M. (2003). Heterosexually active men's beliefs about methods for preventing sexually transmitted diseases. Perspectives on Sexual and Reproductive Health, 35, 121-129.

Gross, J. (1985, October 14). Bathhouses reflect AIDS concerns. New York Times, p. B3.

Institute for the Advanced Study of Human Sexuality. (1986). Safe sex in the age of AIDS. Secaucus, NJ: Citadel Press.

Kippax, S., \& Race, K. (2003). Sustaining safe practice: Twenty years on. Social Science \& Medicine, 57, $1-12$.

Lancet. (2002). Abstinence, monogamy and sex (Editorial). Lancet, 360:97.

Lattin, D. (1989, November 6). Catholic bishops "safer sex" guidelines blasted. San Francisco Chronicle, p. A9.

Lindsey, R. (1985, October 24). Bathhouse curbs called help in coast AIDS fight. New York Times. p. A19.

Miller, J. (1986, October 5). Prostitutes make appeal for AIDS prevention. New York Times, p. A9.

Morin, S. F., Charles, K. A., \& Malyon, A. K. (1984). The psychological impact of AIDS on gay men. American Psychologist, 39, 1288-1293.

Moskowitz, J. M., Henneman, T. A., \& Young Holt, B. (2002). California 2000 HIV/AIDS Knowledge, Attitudes, Beliefs, and Behaviors (KABB) Survey: Methods and Results. Berkeley, CA: Center for Family and Community Health, University of California, Berkeley. Retrieved June 29, 2005, from http://cfch.berkeley.edu/reports/KABBTech Nov12.pdf

Nordheimer, J. (1986, September 22). Campuses press efforts on awareness of AIDS. New York Times, p. A14.

Slevin, A. P., \& Marvin, C. L. (1987). Safe sex and pregnancy prevention: A guide for health practitioners working with adolescents. Journal Community Health Nursing, 4, 235-241.

Stata Corporation. (2003). Stata statistical software: Release 8.0. College Station, TX: Author.

UCLA Center for Health Policy Research. (2002). CHIS 2001 methodology series: Report 4 - Response rates. Los Angeles, CA: Author. Retrieved June 29, 2005, from http://www.chis.ucla.edu/pdf/CHIS2001_method4.pdf

Werner, L. (1987, February 11). Koop urges TV condom ads to fight AIDS. New York Times, p. A1. Whitmore, G. (1985, May 19). Reaching out to someone with AIDS. New York Times, p. SM68.

\title{
Acknowledgements
}

The authors would like to thank Biao Xing, of the University of California, Berkeley, School of Public Health, for biostatistical consultation, and Dr. Juan Ruiz of the Office of AIDS for editorial suggestions.

Preparation of this manuscript was supported through a contract from the California Department of Health Services, Office of AIDS (\#00-91180) and cooperative agreements from the Centers for Disease Control and Prevention (\#U48/909706, \#U48/DP000033).

\author{
Author Information \\ Joel M. Moskowitz, PhD \\ University of California, Berkeley \\ Center for Family and Community Health \\ School of Public Health \\ 140 Warren Hall \\ Berkeley, CA 94720-7360 \\ Ph.: 510-643-7314 \\ Fax.: 510-643-7316 \\ E-Mail: jmm@berkeley.edu
}




\author{
Assunta Ritieni \\ Maya Tholandi \\ Qiang Xia \\ California Department of Health Services \\ Office of AIDS
}




\section{Appendix A}

Unweighted and Weighted Characteristics of the Study Sample:

California Adults, $2000(\mathrm{~N}=1698)$

\begin{tabular}{|c|c|c|c|c|}
\hline Variable & $\begin{array}{c}\text { Unweighted } \\
\mathbf{N}\end{array}$ & $\begin{array}{c}\text { Unweighted } \\
\% \\
\end{array}$ & $\begin{array}{c}\text { Weighted } \\
\%\end{array}$ & $\begin{array}{c}95 \% \\
\text { Conf. Int. }\end{array}$ \\
\hline \multicolumn{5}{|l|}{ Sex } \\
\hline Female & 1,020 & 60.1 & 49.5 & $46.6,52.4$ \\
\hline Male & 678 & 39.9 & 50.5 & $47.6,53.4$ \\
\hline \multicolumn{5}{|l|}{ Age Group (in years) } \\
\hline $18-25$ & 257 & 15.1 & 13.0 & $11.3,14.0$ \\
\hline $25-44$ & 766 & 45.1 & 44.0 & $41.1,46.8$ \\
\hline $45-64$ & 460 & 27.1 & 29.3 & $26.6,32.2$ \\
\hline$\geq 65$ & 215 & 12.7 & 13.7 & $11.8,15.9$ \\
\hline \multicolumn{5}{|l|}{ Race/Ethnicity } \\
\hline White & 978 & 57.6 & 54.4 & $51.4,57.3$ \\
\hline African-American & 131 & 7.7 & 6.8 & $5.6,8.2$ \\
\hline Hispanic & 447 & 26.3 & 26.5 & $24.0,29.2$ \\
\hline Other & 142 & 8.4 & 12.4 & $10.0,15.2$ \\
\hline \multicolumn{5}{|l|}{ Education (in years) } \\
\hline$<12$ & 247 & 14.6 & 16.1 & $14.0,18.5$ \\
\hline 12 & 475 & 28.0 & 27.1 & $24.6,29.7$ \\
\hline $13-15$ & 460 & 27.1 & 26.1 & $23.7,28.7$ \\
\hline$\geq 16$ & 516 & 30.4 & 30.7 & $28.1,33.5$ \\
\hline \multicolumn{5}{|c|}{$\begin{array}{c}\text { Number of Sexual Partners } \\
\text { in Prior } 12 \text { Months }\end{array}$} \\
\hline 0 & 396 & 23.3 & 20.1 & $18.0,22.4$ \\
\hline 1 & 1,120 & 66.0 & 70.6 & $68.0,73.1$ \\
\hline$\geq 2$ & 182 & 10.7 & 9.3 & $7.8,11.0$ \\
\hline
\end{tabular}

